\title{
Os figurinos de Les Éphémères
}

\author{
Entrevista com \\ Marie-Hélène Bouvet
}

ala Preta: Qual a diferença em fazer figurinos cheios de inspiraçôes de época, como nos espetáculos anteriores do Soleil e, agora, para um registro contemporâneo?

Marie-Hélène: Depois de ter trabalhado muito com roupas de época, com figurinos propriamente ditos, eu já não sabia mais como fazer o contemporâneo. Então, para Le Dernier Caravanserail, que também tem figurinos do dia-a-dia, cada um de nós, entre as pessoas da companhia, trouxe muitas, muitas roupas contemporâneas. E também pedíamos doações aos amigos. Assim, não compramos muita coisa. $\mathrm{E}$, de repente já tinha uma pilha de roupas, que tivemos que falar: chega! [risos] Aí, classificamos tudo por gêneros: calças, camisas, saias, roupas de trabalho, roupas de sair etc. Então, quando os atores começavam a procurar suas personagens, eles olhavam para ver como poderiam fazer a construção. E as figurinistas ao lado deles o tempo inteiro, para auxiliar. Eles falavam da personagem que iriam fazer, porque trabalhariam sobre a improvisação, e aí procurávamos o tipo de figurino que corresponderia a cada personagem. É o ator que escolhe a sua personagem. Há atores que sabem muito bem se vestir sozinhos. Há outros que não sabem muita coisa. E assim também acontece com as bijuterias, os adereços, tudo que tenha a ver com a personagem.

Sala Preta: Você pode nos falar um pouco de como foi o processo de criação da personagem Perle?

Marie-Hélène: A personagem de Perle começou a se criar na cabeça da Shasha (como é chamada a atriz Shaghayegh Beheshti) no Afeganistão, quando Ariane realizou um estágio para os atores afegãos, jovens estudantes de teatro da Universidade de Cabul, em 2005. Eram uns trinta atores, sendo que somente três mulheres. Levamos figurinos do Théâtre $d u$ Soleil, e também muitas coisas, da Ópera de Paris, Commedie Française, doações de figurinos e materiais para criar uma companhia teatral no Afeganistão. Levamos cenários, adereços, o máximo de coisas possíveis. Os atores do Soleil também estavam lá com os atores afegãos e eles trabalhavam juntos. Era um estágio de máscaras. A esta época, Shasha trabalhava a Madame Pantalon, da Commedia dell'Arte. Geralmente uma personagem masculina, mas ela quis fazer. E lá começou a trabalhar sua voz, sua postura...

Entrevista realizada por Fausto Viana e Rosane Muniz no Departamento de Artes Cênicas da USP com a presença dos alunos de graduação e pós-graduação do curso de Artes Cênicas. Tradução de Rosane Muniz. 
Era completamente diferente do que é a Perle hoje, mas ali começou o trabalho. Então, durante a criação de Os Efêmeros, ela propôs uma personagem que se inspirasse em Madame Pantalon. Essa máscara. E a voz, sobretudo. Assim, a própria atriz, mais que nós, foi criando essa senhora, pouco a pouco, ao fim de cada ensaio. Ela foi trabalhando com a Juliana e, com o assistente de Ariane, finalmente encontrou. Foi um trabalho diário. E quanto aos figurinos, ela usa muita roupa de minha mãe.

Sala Preta: É aí que queríamos chegar... Como isso aconteceu?

Marie-Hélène: Minha mãe partiu para um asilo, estava bem gorda, era costureira e fazia suas próprias roupas. E eu recuperei todas estas roupas, pois ela engordou muito e não cabia mais nelas. Coloquei tudo no meu carro, que ficou cheio de roupas até o teto. Cheguei ao teatro, coloquei tudo sobre as araras e os atores avançaram como moscas. [risos] Assim, há muita roupa da minha mãe no espetáculo: na Gaelle, em personagens da Juliana... E não só nas roupas que eu trouxe. A Liliana, o Jean-Jacques... tem roupa de todo mundo no espetáculo.

Sala Preta: No espetáculo há muitas crianças. Algumas são filhos de atores do elenco, outras foram selecionadas a partir de anúncio que Ariane colocou em escolas, como você nos contou. Algumas estão com a mãe, outras viajam sozinhas com a companhia. Como é vestir estas crianças?

Marie-Hélène: Da mesma maneira. Os atores infantis contribuem da mesma maneira que os adultos. Durante os ensaios, os atores que fazem a improvisação e têm necessidade de uma criança para a cena, trabalham com elas às quartas-feiras, que é o dia que elas não têm escola. E aos sábados. E ainda, aos domingos, às vezes. E durante a noite. Os filhos de atores são mais presentes que os outros. Assim, são eles que encontraram, na maior parte do tempo, as personagens. A não ser Gaelle que foi encontrada por uma menininha, chamada Emmie, que não era filha de um ator. Essa menina encontrou na personagem a sua história. Ela não está mais com a companhia, mas foi ela quem criou esta personagem. E quando os atores começaram a fazer a cena, todos repararam como ela estava interpretando muito bem. Ela chorava em cena e todos olhavam e comentavam: "Olha como ela está bem, interpreta muito bem, que atriz boa, chora sem parar...” E depois descobrimos que ela tinha perdido seu pai seis meses antes. Então, ela tinha ficado muito fortemente tocada pela cena. E dissemos "é exatamente assim que tem que ser interpretada esta personagem". Então, as outras crianças depois interpretaram como ela. As crianças não podem atuar todos os dias, por isso os papéis infantis trocam de atores a cada dia. Inclusive nas turnês, também há trocas.

Sala Preta: O que lhe dá mais prazer: o clássico ou o contemporâneo?

Marie-Hélène: É muito diferente. Aprendi a descobrir o prazer de trabalhar com o figurino contemporâneo. Para que o figurino seja adequado, é mais difícil. É contemporâneo, é como nós. Então, tem que ser bem trabalhado com o ator, com a personagem. E, sobretudo, que pareça natural. E que seja adequado à personagem. Bem adequado como a gravata, a calça, o sapato, as meias. Aprendi a ter prazer.

Sala Preta: Percebi as cores do espetáculo bem clássicas: o preto, branco, bege, cáqui. Nenhuma estampa. Foi a proposta?

Marie-Hélène: Isso veio naturalmente. Veio, evidentemente, com a história, com as cenas. É que não é o figurino que queremos ver, mas a personagem.

Sala Preta: Como é o dia-a-dia de Os Efêmeros? Quantos figurinos há ao total?

Marie-Hélène: Não sei. Não posso dizer mais isso hoje. Quando saímos em turnê, colocamos tudo dentro dos cestos, dos caminhões, dos aviōes, dos barcos. Arrumamos por atores. Há sempre ensaios, em cada local de turnê. Assim, antes falamos, "vejam se vocês têm tudo!" Controlamos, mas não podemos controlar tudo. Então, cada um olha. Algumas vezes há uns que não olham nada.

Sala Preta: Mas há uma lista? 
Marie-Hélène: Não, não, não. Jamais! É impossível Não estamos sós, trabalhamos juntas. Não há necessidade de decorar tudo.

Sala Preta: Como é a função das figurinistas durante o espetáculo?

Marie-Hélène: Para Os Efêmeros, somos só nós: Nathalie e eu. Durante os ensaios, estamos por lá... de repente, chega um e diz "preciso que você me ajude em uma troca rápida”, aí estou lá. E, pouco a pouco, nós vamos entendendo o que devemos fazer, onde devemos ajudar, pois trabalhamos o tempo todo com eles. Por exemplo, se há uma troca de roupa que deve ser feita rápida, nós preparamos o figurino, todos os acessórios e quando o ator sai da cena, nós fazemos a troca, às vezes em um minuto. Se precisar mudar a peruca, o penteado, o figurino...

Sala Preta: Quem é responsável pelas perucas?

Marie-Hélène: Jean-Sébastien, que também está aqui conosco. Ele segue os atores, faz os penteados. Mas até eu, por exemplo, faço o cabelo de um, a trança da outra, porque ele não pode estar em todos os lugares. Eu maquio as crianças quando chegam vermelhos na cena da praia. "Vocês estão vermelhos! Vermelhos como um tomate!" então eu maquio tudo de vermelho: o rosto, os braços, as pernas... depois eu tiro a maquiagem, depois também tiro a maquiagem das pernas de Perle...

Sala Preta: Depois do espetáculo, qual a função de vocês. Porque depois dos ensaios, vimos alguns atores que saíam de cena e foram empilhando seus figurinos na lavanderia.

Marie-Hélène: Nós dizemos que assim que o espetáculo termina, assim que os atores retornam ao seu camarim, eles se despem. Se a camisa precisa ser lavada, é ele que a leva à lavanderia. Às vezes, não fazem nada disso. Com os atores que vestimos sempre, olhamos se a roupa está apropriada ou não e mandamos lavar. Mas todos os dias, depois dos espetáculos, eles tiram a blusa e a calça de baixo e levam para lavar. A roupa de baixo é muito importante porque protege o figurino. Sobretudo, da transpiração.
Sala Preta: E quando são figurinos históricos, pesados?

Marie-Hélène: Sobretudo nestes! Porque os figurinos históricos são lavados o menos possível. Os produtos de lavanderia estragam muito os figurinos. A roupa de baixo é uma t-shirt com uma ceroula. Quando fui à Taiwan para Tambores sobre o dique, visitei a escola da Ópera Chinesa. E visitei também o setor de figurinos, é lógico. Muito lindo. E fiz a pergunta: "como vocês fazem para lavar esses figurinos?”. Nunca mando para uma lavanderia ou tinturaria. Eles possuem pequenos vaporizadores de álcool de arroz para desinfetar os figurinos. Este é um método ancestral. E é só isso! Desta forma, o figurino está sempre novo: as cores. Usei este mesmo método com os figurinos de os Tambores. Os figurinos de Os Átridas, por exemplo, quando iam para lavar, sempre voltavam com necessidade de restaurações. Assim, sempre preferimos lavar a mão. Os figurinos com o coro, as danças, eram muito pesados e transpiravam muito. Mandei os figurinos do coro de Ifigênia para a lavanderia e quando voltaram... a parte de cima era vermelha e fixada, costurada com as saias, que eram brancas. Quando mandamos para a tinturaria, as saias voltaram rosas. E tínhamos apresentação à noite. Marie-Hélène chorava!! [risos] E eram quatorze figurinos! Liguei para a Liliana e todos vieram ajudar. Descosi todas as saias e fizemos outras. Todo o Théatre du Soleil se ocupou deste trabalho. Liliana atendia o telefone para reservar ingressos e não parava de costurar ao mesmo tempo. [risos] Agora, unimos duas peças com ilhoses e laços. Assim, fica firme do mesmo jeito e podemos separar para lavar quando necessário. Para tirar o mau-cheiro, na França utilizamos um produto que se chama Febrèse.

Sala Preta: E vocês têm necessidade de substituir algum figurino depois da estréia?

Marie-Hélène: Por causa do desgaste? Sobretudo se houve algum acidente. Mas eu sempre tento encontrar uma solução. Quando viajamos em turnê, temos muitos acidentes. Nessa viagem, por exemplo, o Duccio, que faz 
o oficial de justiça que vai avaliar os bens do casal que deve, deixou uma caneta dentro do bolso e vazou sobre o impermeável. Manchou o casaco dele, mas também o jaleco branco de Nelly, a médica interpretada pela Juliana e que contracena com a Perle. Teve uma outra catástrofe. A camisola da Perle foi mandada a lavar e voltou com uma grande macha branca. O sabão em pó daqui é muito forte, tem cândida. Quando a máquina lavou, ele estava mal diluído e manchou, deixando uma grande mancha branca na frente. Tivemos que mandar comprarem outra camisola para substituir.

Sala Preta: Quem assina os figurinos?

Marie-Hélène: Nathalie, eu e Annie também. Trabalhamos juntas. Uma sem a outra, não seríamos nada. Annie é asiátiaca, é precisa e perfeita, e trabalha mais na máquina de costura. Nathalie é especializada no corte. E eu, me adapto.

Liliana: Há um pouco de todos nos cenários e figurinos. A assinatura, na verdade, é coletiva. Mas naturalmente há uma relação distinta. Annie tem uma relação com a máquina de costura, faz quase tudo e muito bem. Nathalie tem uma formação clássica de costura de teatro. Então, para ela, é muito mais fácil interpretar sobre o molde uma idéia que lhe dão. A importância da Nathalie é, sobretudo, nas obras clássicas. E Marie-Hélène tem um dom que para o Soleil é precioso, que é saber interpretar o que Ariane, às vezes, não sabe dizer com as palavras. E buscar uma solução a uma idéia de Ariane, que tem que ser muito rápida. E a interlocutora para isso é Marie-Hélène. A magia de encontrar a solução rápida e com calma é Marie-Hélène. Depois que ela encontra a solução, entra a Nathalie para organizar de outra maneira e Annie para fazer a costura.

Marie-Hélène: $\mathrm{O}$ que acho importante quando vou fazer esse trabalho é de ter uma visão global, bem conectada com as personagens, para depois fazer a proposta. Parece muito fácil, já que é uma maneira de trabalhar ideal. Porque estamos ao lado do ator. Não fabricamos um figurino que depois o ator vem, deixa, às vezes nem ensaia vestido... Frequentemente há atores que não querem ensaiar. Eu costumo dizer que, se um dia eu deixar o Théatre du Soleil, não farei mais figurinos em outro lugar. Porque em outro lugar, não me interessa desta forma.

Sala Preta: Você conhece outras companhias que trabalham desta maneira?

Marie-Hélène: Há pessoas que saíram do Soleil e formaram sua própria trupe. E Ariane fala sempre aos atores para fazerem seus grupos, que é isso que salvará.

Sala Preta: Você disse, em uma entrevista, que os atores têm liberdade de criar até certo ponto. Que, por exemplo, a forma, quem define é você. Qual o ponto de limite onde você fala "chega! Agora é comigo"?

Marie-Hélène: Quando eles falam besteira! [risos] Quando eles falam coisas que não são realizáveis. Aí, nós fazemos nossas propostas: "não! É assim, assado...". E eu falo "isso funciona, isso não funciona. Dá pra fazer, não dá pra fazer".

Sala Preta: Gostaria de saber se os objetos de cena para criação do cenário também foram adquiridos da mesma forma que os figurinos.

Marie-Hélène: Sim, sim. Fizemos um verdadeiro bazar de tudo. Cada um que passava na rua e via um objeto, passava com o carro e pegava tudo. Pela manhã, chegávamos cheios de coisas, organizávamos por estilos e depois, os atores quando faziam suas proposiçóes, iam pegando o que interessava à sua cena.

Liliana: É que em Paris, um dia por mês, quem compra muito, póe para o lado de fora da casa o que não quer mais. Cada bairro tem o seu dia. E pode-se pôr tudo o que não se quer mais: bancos, roupas... Então, nesse dia, geralmente há muitas pessoas que passam para buscar as coisas que lhe interessem. $\mathrm{E}$ os atores sabiam qual era o dia de cada zona, e também qual era a zona mais interessante. Então, iam com os carros à noite e carregavam de coisas. Jeremy James (o ator que interpreta Sandra), que é um grande obsessivo com estes materiais, era o responsável pela organização dos objetos: as lâmpadas, os pratos etc. Então, quando o ator 
tinha uma idéia, ia lá buscar o objeto adequado. Também é muito interessante saber que os atores chegam muito cedo pela manhã, há uma reunião com a Ariane todos juntos para começar o dia, para definir o trabalho, planificar o que se vai fazer. E, neste minuto, Ariane diz o que vai querer fazer: treze cenas, repetir doze cenas que já fizeram e voltarão a trabalhar, ou improvisar sobre novas cenas... Então, durante toda a parte da manhã e parte da tarde, os atores têm que preparar-se psicologicamente, juntar-se com um grupo para compartir uma idéia, fabricar uma cena juntos, eleger os figurinos e os objetos que irão utilizar. Uma vez que já possuem tudo isso, pois já fizeram seus aquecimentos e exercícios, é a hora de começar. Isso, mais ou menos, às 16 h30... 17h. Este é um método para agora. Pode mudar. Este é o método que Ariane usou para este espetáculo, no qual não há texto, é todo improvisado. Tudo improvisado, fotografado, filmado e Charles-Henri Bradier, assistente de Ariane, toma nota de tudo no seu computador, inclusive de todas as indicações de Ariane. Por isso que, no programa, é possível ver o caderno de anotaçôes. Com o registro, já se vê o que se tem em mãos. E aí Marie-Hélène vê como vai poder passar isso ou aquilo. Os atores avaliam o que fizeram. Charles-Henri, pela manhã, enquanto os atores se preparam, enquanto invadem Marie-Hélène para pedir: "não tem uma bolsa assim" etc, ele passa todas as suas anotações a limpo, as ilustra com as fotografias numéricas, põe tudo isso em um dossiê organizado por dia. Quer dizer, se a Ariane disser "eu gostaria de voltar a fazer tal cena”, então é possível voltar a esse dia, que está todo classificado, e ver do que Ariane está falando, o que aconteceu, ver na foto como estava tudo, pedir a roupa para a Marie-Hélène, que já tem tudo isso separado. Mas, às vezes, os atores roubam uma coisa de um personagem, aí Marie-Hélène tem que sair correndo para buscar e reconstituir o primeiro conjunto. Este é todo o operativo desta máquina de criação, que não é simples.
Sala Preta: E esses objetos de cena foram escolhidos pelos atores? Porque, neste espetáculo, é possível fazer uma leitura da classe social, estilo, informaçóes da vida da personagem que ali habita, em cada cenário apresentado.

Liliana: Para cada espetáculo há muitíssima documentação. Escrita, de fotos, filmes, livros... Os atores têm todo o momento para trabalhar com informações. Para quem não sabe, convidamos pessoas. Por exemplo, na cena de Perle e da médica convidávamos médicos que trabalhavam com uma pessoa em caso terminal, para saber o que passa, qual suas reaçóes... Vai-se à escola cada vez. O mesmo com a arquivista, uma pessoa que mostrava o trabalho, explicava como era, fomos todos aos arquivos... É um grande aprendizado, como uma viagem. Fazemos todos juntos. Desta vez, foi assim. De outra vez, fomos ao Cambodja ou à Índia. Ou com as comidas, os odores, as personagens, as fotos... Tudo isso faz com que a imaginação trabalhe, se gere imagens, idéias. E é sem volta. Marie-Hélène não trabalha ilhada, mas com todos, e com a imaginação que está criando a partir de informações que recebe.

Sala Preta: No processo de criação há utilização dos desenhos de figurinos?

Marie-Hélène: Não. Não desenhamos. Porque não podemos prever um traje antes que $\mathrm{o}$ ator encontre sua personagem. Pode-se dizer que a personagem se cria ao mesmo tempo que sua indumentária. Mesmo para os figurinos de época, não há desenhos.

Liliana: Nathalie corta sobre os atores. E ela guarda tudo isso, pois se for necessário refazer, faz-se uma reforma a partir do molde inicial. É uma moulage em tecido bege, branco...

Sala Preta: Uma palavra final?

Marie-Hélène: Eu queria falar para os futuros figurinistas e cenógrafos que, mesmo quando não temos muitos meios, podemos conseguir fazer muitas coisas. Porque se utilizamos a imaginação, ela chega muito de repente quando de uma calça se faz uma touca ou quando de uma touca podemos fazer uma perneira. 
Misturar as coisas. É necessário utilizar-se disso porque é muito importante, na minha opinião, para encontrar as coisas novas. Sobretudo, faça trabalhar a imaginação. E não é porque não temos os meios que não podemos fazer coisas bonitas. Outra coisa, que a Ariane tem muito, foi quando fizemos os figurinos de Os Átridas ou do ciclo de Shakespeare, é que a terminação das mãos e dos pés é muito importante. E também as golas. Muitas bijuterias segurando as mangas, que normalmente cobrem metade das mãos. Os detalhes são sempre importantes. Detalhes que parecem que não se vêem, mas que complementam. Sobretudo, que as roupas tenham terminaçôes. Quando o ator chega, às vezes falo: “vá finalizar, vá terminar seu figurino". Pode ser um bracelete, um punho, uma polaina, mas que se termine a roupa. A idéia não é fechar, mas dar um acabamento, um suporte. No contemporâneo já é um pouco diferente. Mas tem sempre que se pensar no pequeno pra chegar ao grande. Então, o detalhe é muito importante.

Sala Preta: E estes detalhes já são pensados desde o primeiro dia de ensaio também?

Marie-Hélène: Sim. Muitas vezes o primeiro dia de ensaio é muito rigoroso. Por exemplo, as máscaras de Tambores sobre o dique foram criadas desde o primeiro dia de ensaio, para todo o elenco, para as marionetes. Foram feitas com meias-calças, com espumas por baixo dando enchimento nas bochechas. Os atores faziam todos os dias, desde o primeiro ensaio. 